\title{
COMPLEXIDADE DA DOCÊNCIA NOS ANOS INICIAIS DO ENSINO FUNDAMENTAL: ANÁLISE SOBRE ENTREVISTAS
}

\author{
Alana Silva Moreira, Vanda Moreira Machado Lima \\ Universidade Estadual Paulista - UNESP, Curso de Pedagogia, Presidente Prudente, São Paulo. E-mail: \\ alanasmoreira@gmail.com \\ Agência de fomento: PIBIC-ISB/UNESP
}

\section{RESUMO}

O texto em questão é resultado de uma Pesquisa de Iniciação Científica cujo o objetivo foi investigar a complexidade da docência nos anos iniciais do Ensino Fundamental em uma escola pública municipal. Utilizamos como base 95 horas de observação participante e 4 entrevistas semiestruturadas, realizadas com professoras polivalentes. Para tanto utilizamos a pesquisa do tipo qualitativa, que envolve técnicas de observação participante, estudo bibliográfico e registro reflexivo, além de técnicas de análise de conteúdo. Constatamos que a complexidade em ser professor dos anos iniciais na escola pública municipal envolve a clareza de seu papel como formador e agente de transformação, que enfrenta diversos desafios em sala de aula, como classe numerosa, indisciplina, falta de apoio familiar, entre outros. Entretanto, as alegrias ao constar a evolução e desenvolvimento da aprendizagem de seus alunos são ressaltadas em todas as falas.

Palavras-chave: Professor dos Anos Iniciais, Escola Pública, Complexidade da docência nos anos iniciais.

\section{TEACHING COMPLEXITY IN EARLY YEARS OF ELEMENTARY SCHOOL: ANALYSIS OF INTERVIEWS}

\begin{abstract}
The text in question is the result of a scientific initiation research whose aim was to investigate the complexity of teaching in the early years of elementary school in a public school. The base of 95 hours of participant observation and 4 semi -structured interviews conducted with polyvalent teachers. For this, we use the qualitative study, involving participant observation techniques, bibliographic study and reflective record, and content analysis techniques. We found that the complexity of being a teacher in the early years in the public school involves the clarity of its role as a trainer and agent of change, facing many challenges in the classroom, such as large class, indiscipline, lack of family support, among others. However, the joys to contain the evolution and development of learning of their students are highlighted in all lines.
\end{abstract}

Keywords: Professor of Early Years, Public School, teaching Complexity in the early years. 


\section{INTRODUÇÃO}

A construção de uma escola pública dos anos iniciais democrática, inclusiva, reflexiva e de qualidade ainda é um grande desafio, que envolve vários fatores (LIMA, 2012). O professor constitui-se como um elemento primordial na construção de uma sociedade crítica, reflexiva e democrática, visto que atua diretamente na formação de crianças. Contudo, a profissão professor enfrenta diariamente uma série de desafios que tornam sua prática cotidiana complexa. $\mathrm{O}$ artigo em questão é um fragmento de uma pesquisa de Iniciação científica reconhecida sem bolsa (PIBIC/ISB/UNESP), que visou investigar a complexidade da docência nos anos iniciais do ensino fundamental (EF) sob a ótica de professoras que lecionam no $1^{\circ}$ ano do EF em uma escola pública municipal de Presidente Prudente, SP.

\section{METODOLOGIA}

Desenvolvemos uma pesquisa do tipo qualitativa que estuda os fenômenos que envolvem os seres humanos e suas relações sociais. Para Lüdke e André (1986) na pesquisa qualitativa o ambiente é o principal instrumento, como fonte direta de dados, com contato direto e prolongado do pesquisador com o que está sendo investigado mediante trabalho intensivo de campo e análise de todos os dados. No caso desse estudo, escolhemos uma escola pública municipal e professores polivalentes que atuam nos anos iniciais do ensino fundamental.

Como instrumentos para coleta de dados utilizamos o estudo bibliográfico, observação/ participação e entrevistas semiestruturadas. No estudo bibliográfico desenvolvemos um levantamento de pesquisas e publicações envolvendo nosso objeto de estudo, o que fundamentou a análise dos dados coletados, além das questões relacionadas à metodologia da pesquisa.

A realização da observação/participação se desenvolveu no período de agosto a novembro de 2015 e de março a maio de 2016, mediante a presença da bolsista uma vez por semana nas aulas de duas professores que lecionam no $1^{\circ}$ ano do $E F$, totalizando $95 \mathrm{~h}$ horas. A observação participante permite que o pesquisador se envolva "com os sujeitos em seu cotidiano, tentando sentir o que significa estar naquela situação" (REYS; MONTEIRO, 2010, p. 19). Ao fim das observações, constatamos que ser Professor Polivalente na escola pública é uma tarefa complexa e repleta de desafios, contudo, constatamos possibilidades de atuar com qualidade e alegrias na prática docente cotidiana.

As entrevistas semiestruturadas foram desenvolvidas com quatro professoras polivalentes que lecionam no $1^{\circ}$ ano do EF na escola pesquisada. Fizemos seis questões às entrevistadas, que em linhas gerais abordaram os desafios, alegrias e papel docente na escola pública.

Esta pesquisa foi aprovada pelo comitê de ética, sob o número 27133714.3.0000.542.

\section{RESULTADOS}

Apresentamos como resultados os aspectos sobre o papel da escola pública municipal e do professor; as dificuldades e alegrias docentes presentes no cotidiano escolar

Ao indagarmos as professoras sobre o papel da escola, duas enfatizaram o aspecto de ascensão social, visto que a educação e o conhecimento são essenciais para a mudança social na vida das crianças que provém de uma comunidade carente. Outro elemento apontado foi a função da escola ser espaço de formação do cidadão (2 professoras), assegurando uma formação que possibilite uma atuação crítica na sociedade. Também foi citado a compreensão da escola como espaço de um ensino sistemático que propicie base para a continuidade dos estudos ( 2 professoras).

A escola é o único espaço institucional que pode abrigar as camadas populares; contudo não basta apenas oferecer uma vaga, é preciso desenvolver um ensino que vá eliminando gradativamente a dualidade da educação brasileira, com a construção de uma escola igualitária, que possa ser frequentada por todos sem distinção de raça, cor ou sexo (VALE, 1997). 
Em relação ao papel do professor que atua nos anos iniciais do EF na escola pública municipal, três sujeitos afirmaram que a função docente é garantir a base de conhecimentos das crianças, enfatizando o seu papel como alfabetizadora (2) e promovendo a criticidade e a autonomia as crianças (1). O papel de educar foi apontado uma vez.

Libâneo (2010) defende que o papel específico do professor é na promoção da aprendizagem dos alunos, na formação de capacidades cognitivas por meio do ensino dos conteúdos escolares associados com formas de interação social nos processos de aprendizagem no contexto sociocultural. É ajudar os alunos na resolução de problemas aos quais eles não sabem resolver, oferecendo e possibilitando o desenvolvimento de estratégias para que, gradativamente eles possam resolvê-los de maneira independente. Esse processo requer que o professor interaja os conhecimentos já adquiridos pelas crianças ao conhecimento novo, criando formas de interação cognitiva que amplie o desenvolvimento mental de seus alunos.

Dessa forma, "o educador deve ser um suporte e guia para a aprendizagem, bem como um potencial mediador e modelador de um processo motivacional significativo" (BARBOSA; CAMPOS; VALENTIM, 2011, p. 454)

A docência é uma atividade intelectual, técnica, moral e racional que agrega dimensões teóricas, técnicas e políticas. "Dessa forma, a docência é um ofício em que o professor aprende e ensina ao formar-se, e muitos são os saberes e vivências que permeiam suas práticas" (CRUZ, 2012, p. 139).

Ser professor dos anos iniciais do EF envolve atuar em diferentes disciplinas, no qual a interdisciplinaridade é elemento relevante. As professoras entrevistadas atuam no 10 ano lecionando as disciplinas de Língua Portuguesa, Matemática, Ciências, História, Geografia, Arte e Educação Física.

Todas as professoras apontaram de modo positivo para a interdisciplinaridade. Esse processo, segundo as entrevistadas ocorre mediante o Método Sociolinguístico, por meio da utilização das palavras geradoras são trabalhados outros conteúdos.

Nas observações constatamos o desenvolvimento do Método Sociolinguístico. Por exemplo, no trabalho com a palavra geradora "Família" as professoras propuseram um diálogo com as crianças sobre suas famílias e seus conhecimentos sobre o assunto relacionando outras disciplinas.

No Método Sociolinguístico, com o uso das palavras geradoras, o professor realiza a Codificação e a Descodificação, ouvindo os alunos e intervindo em suas concepções ingênuas por meio de diversos materiais, no intuito de tornar esse conhecimento sistematizado, crítico e significativo, além de promover a alfabetização em contexto de letramento (MENDONÇA; MENDONÇA, 2010).

Cruz (2012) aponta a questão da interdisciplinaridade como parte da organização do trabalho docente nos anos iniciais. Contudo, em nossa pesquisa, embora o trabalho seja apontado pelas professoras como interdisciplinar verificamos a ênfase para a aquisição de conhecimentos e habilidades ligados à escrita, para alfabetização, enfim um trabalho relevante com a disciplina de Língua Portuguesa.

Ressaltamos também a questão da formação inicial do professor, que não o prepara para atuar de forma interdisciplinar, e reiteramos que as políticas recentes para a formação de professores dos anos iniciais não vem apontando melhorias para a ruptura da tradição disciplinar. Duas entrevistadas apontaram para a dificuldade em se trabalhar de forma interdisciplinar.

Quanto às dificuldades no trabalho docente, as professoras apontaram:

- Quantidade de alunos por sala, atualmente 28, o que dificulta o trabalho, principalmente no $1^{\circ}$ ano onde as crianças precisam de uma atenção individual no processo de alfabetização (2). 0 Plano Municipal de Educação, estratégia 17.7 prevê para as classes dos cinco primeiros anos do ensino fundamental o máximo de 25 alunos até 2020 (PRESIDENTE PRUDENTE, 2015). 
- Estrutura da escola, em especial a sala de informática que necessita de melhorias (1). Esse fator merece destaque, pois depende de investimentos do poder público, no caso da Secretaria Municipal de Educação. Infelizmente, constatamos que os tais investimentos com educação não tem sido suficientes para assegurar um ensino público de qualidade.

- Indisciplina foi apontada como um elemento dificultador (2). Aquino (1988), afirma que ao eleger um aluno indisciplinado como empecilho ao trabalho pedagógico, corre-se o risco de cometer um equívoco ético de atribuir a clientela escolar a responsabilidade pelas dificuldades e contratempos do trabalho pedagógico. Contudo, a indisciplina vem ocupando cada vez mais espaço no cotidiano escolar, acarretando em insatisfação, surgimento de doenças e até mesmo abandono do magistério.

- Ausência de apoio familiar foi mencionado (2). Nesse sentido, Lima (2012), traz a importância da cautela ao analisar o papel da família no processo de ensino-aprendizagem, apontando a necessidade de reflexão sobre que tipo de apoio a escola espera de fato da família.

Apesar de tantas dificuldades evidenciadas, as professoras entrevistadas também apresentaram elementos que trazem alegrias em seu trabalho no cotidiano escolar. Constatamos que vivenciar o processo de aprendizagem do aluno é o elemento de maior alegria. As professoras afirmam que o aluno chega ao início do ano sem saber escrever o nome, sem conhecer as letras, depois vai conhecendo o alfabeto, vai aprendendo a juntar sílabas, formar palavras e até elaborar pequenas frases. Isso é algo que traz grande satisfação e alegria para a prática docente.

Diariamente, o professor polivalente atua com a mesma sala, estabelecendo um vínculo afetivo, o que possibilita melhor compreensão das dificuldades das crianças, de sua história de vida. Percebemos nas observações claramente essa relação de afetividade nas salas do $1^{\circ}$ ano no decorrer da pesquisa.

Lima (2012, p. 158) também identificou em sua pesquisa que "a maior alegria em ser professor dos anos iniciais consiste na interação com a criança, no conviver com sua espontaneidade, no constatar os avanços e o desenvolvimento da criança no processo ensinoaprendizagem".

A relação com a afetividade está associada a diversas consequências escolares importantes, como: a confiança dos alunos em relação as suas capacidades, percepção do ambiente escolar como um apoio, mais confiança para expressar seus sentimentos e preocupações, prevenir problemas disciplinares, etc. (BARBOSA; CAMPOS; VALENTIM, 2011).

Ao questionarmos sobre qual sala preferiam lecionar, elas foram unânimes. Todas as entrevistadas afirmaram seu interesse pelo $1^{\circ}$ ano argumentando como motivos o carinho, a afetividade, o vínculo e, principalmente o avanço nítido na aprendizagem das crianças.

Ao final da entrevista solicitamos que os entrevistados dessem um conselho para uma futura professora em processo de formação inicial. As entrevistas afirmaram ser essencial ter coragem, paciência, dedicação e gostar de crianças. Aconselharam a sempre trabalharmos em equipe com as demais professoras e a equipe gestora. Uma professora aconselhou a investir no mestrado e doutorado, por conta da desvalorização salarial e profissional do professor atualmente.

\section{DISCUSSÃO}

Apesar de toda a produção acadêmica sobre o que é ser professor e a relação deste com as políticas de formação e profissionalização, pouco se tem discutido sobre a condição do docente dos anos iniciais do ensino fundamental ser aquele que leciona todas as áreas de conhecimentos do currículo da educação básica. Autores como Lima (2012) e Cruz, Batista Neto (2013) defendem a necessidade de reflexão sobre a polivalência presente na atuação do professor dos anos iniciais do EF.

O termo polivalente vem sendo comumente utilizado no mercado de trabalho, 
principalmente no período pós-crise do capitalismo, designando esse profissional como aquele que exerce diversas funções (CRUZ; BATISTA NETO, 2012). Já no âmbito educacional, entendemos o professor polivalente como aquele que atua nos anos iniciais do Ensino Fundamental e leciona diversas áreas do conhecimento, buscando desenvolver um ensino de qualidade, formando um cidadão crítico.

A identidade polivalente foi construída ao longo do tempo, mediante a organização histórica da escola de educação básica, onde um único professor era responsável por lecionar todas as matérias do currículo. Essa condição se perpetuou até os dias atuais, mesmo que a escola e sua função tenham sido totalmente modificadas, assim como sua estrutura e o número de alunos (CRUZ, 2012).

O professor dos anos iniciais "tem um papel importante para a classe trabalhadora. Ele é o responsável por transmitir conhecimentos básicos, promover o questionamento, o senso crítico, a reflexão, além de alfabetizar, ensinar a ler e a escrever, a ler a vida, a lutar por ela" (LIMA, 1997, p. 79).

Enfim, constatamos que a complexidade em ser professor dos anos iniciais na escola pública municipal envolve a clareza de seu papel como formador e agente de transformação, que enfrenta diversos desafios em sala de aula, como classe numerosa, indisciplina, falta de apoio familiar, entre outros. Entretanto, se alegra ao constar a evolução e desenvolvimento da aprendizagem de seus alunos.

\section{CONCLUSÕES}

Defendemos que o verdadeiro papel do educador na sociedade em que vivemos, é de um agente de transformação, comprometido com a classe à qual pertence. Ao proporcionar uma educação de qualidade a seus alunos, esse professor estará oferecendo elementos para sua conscientização política e crítica.

Ser professor é uma atividade ampla, que vai além da sala de aula, envolve relações com os demais profissionais da educação da escola, com as famílias das crianças, com os profissionais das secretarias municipais de educação, com outros profissionais. Enfim ser professor exige assumir responsabilidades políticas, sociais e econômicas.

Para tanto, é preciso que esse profissional conheça bem seu espaço de trabalho, preocupese com a generalização dos conhecimentos historicamente produzidos, assegure a transmissão de conteúdos necessários à instrumentalização prática e teórica para a transformação, busque métodos eficazes de ensino, engaje-se em partidos políticos ou sindicatos para lutar pelas mudanças, e seja coerente com o vivido e o dito (SILVEIRA, 1995).

Atualmente faz-se urgente refletirmos sobre a complexidade da docência nos anos iniciais do EF na escola pública municipal. É necessário considerar os salários baixos, a desvalorização da profissão, a fragilidade na formação inicial e na continuada, o contexto social, econômico e cultural dos nossos alunos, dentre outros fatores. É contraditório que um país que quer educação de qualidade não valorize seus professores.

\section{REFERÊNCIAS}

AQUINO, J. G. A indisciplina e a escola atual. Revista da Faculdade de Educação, v. 24, n. 2, p. 181204, 1998. Disponível em: <ihttp://www.scielo.br/scielo.php?script=sci_arttext\&pid=S0102$25551998000200011>$. Acesso em: 26 jul. 2016.

BARBOSA, A. J. G.; CAMPOS, R. A.; VALENTIM, T. A. A diversidade em sala de aula e a relação professor-aluno. Estudos de Psicologia, Campinas, v. 28, n. 4, p. 453-461, 2011. Disponível em: < http://www.scielo.br/pdf/estpsi/v28n4/06.pdf>. Acesso em: 26 jul. 2016. 
CRUZ, S. P. S. Profissionalidade polivalente e o trabalho docente nos anos iniciais do ensino fundamental. Debates em Educação, Maceió, v. 4, n. 7, p. 134-151, jan./jul. 2012.

CRUZ, S. P. S.; BATISTA NETO, J. A polivalência nos anos iniciais da escolarização básica: refletindo sobre experiências de pesquisa. Revista Brasileira de Educação, v. 17, n. 50, p. 385-397, maio/ago. 2012.

CRUZ, S. P. S.; BATISTA NETO, J. A construção da profissionalidade polivalente na docência nos anos iniciais do ensino fundamental: refletindo sobre elementos estruturantes. Revista Educação e Emancipação, São Luís, v. 6, n. 1, p. 58-75, jan./jun. 2013.

LIBÂNEO, J. C. O ensino da Didática, das metodologias específicas e dos conteúdos específicos do ensino fundamental nos currículos dos cursos de Pedagogia. Revista Brasileira de Estudos Pedagógicos, Brasília, v. 91, n. 229, p. 562-583, set./dez. 2010.

LÜDKE, M, ANDRÉ, M. Pesquisa em educação: abordagens qualitativas. São Paulo. EPU, 1986. 99p. (Temas Básico de Educação e Ensino).

LIMA, V. M. M. A formação do professor da escola básica: um desafio para melhorar a qualidade do ensino público. Nuances: Estudos Sobre Educação, Presidente Prudente, v. 3, n. 3, p. 78-83, set. 1997.

LIMA, V. M. M. A complexidade da docência nos anos iniciais na escola pública. Nuances- estudos sobre educação. v. 22, n. 23. p.151-170, mai/ago. 2012.

MENDONÇA, O. S.; MENDONÇA, O. C. Alfabetização e Letramento: Práticas Socioconstrutivas. São Paulo: Edição dos Autores, 2010.

PRESIDENTE PRUDENTE. Lei n. 8.962, de 9 de outubro de 2015. Aprova o Plano Municipal de Educação - PME, e dá outras providências. [Site oficial da Prefeitura Municipal de Presidente Prudente], out. 2015. Leis e decretos municipais. Disponível em: <http://www.presidenteprudente.sp.gov.br/site/Documento.do?cod=25533>. Acesso em: 26 jul. 2016.

REYS, C. R.; MONTEIRO, H. M. Olhando e observando. In: REYS, C. R.; MONTEIRO, H. M. Um olhar crítico-reflexivo diante da realidade educacional. São Carlos: EdUFSCar, 2010, p. 11-29.

SILVEIRA, R. J. T. O professor e a transformação da realidade. Nuances: Estudos Sobre Educação, Presidente Prudente, v. 1, n. 1, p. 21-30, set. 1995.

VALE, J. M. F. Educação urgente: para que? Nuances: Estudos Sobre Educação, Presidente Prudente, v. 3, n. 3, p. 20-22, set. 1997. 